\title{
Board Games Versus Smartphone Applications: Gaming Media in EFL Contexts
}

\section{Kevin R. Wrobetz \\ Kobe Gakuin University}

\section{Reference Data}

Wrobetz, K.R. (2021). Board games versus smartphone applications: Gaming media in EFL contexts. In P. Clements, R. Derrah, \& P. Ferguson (Eds.), Communities of teachers \& learners. JALT. https://doi.org/10.37546/JALTPCP2020-43

Game-based learning (GBL) has many practical applications in the EFL classroom by promoting interaction with the target language. GBL can, through careful game selection, specifically cater to a wide range of pedagogical strategies, instructional goals, student abilities, and interests. With the host of potential benefits that GBL may have in EFL classrooms, research should not only be focused on whether games can be effective in EFL contexts but also on what types of gaming media are most effective for specific contexts. In this research, two types of gaming media are compared, board game and smartphone application, for Klaus Teuber's The Settlers of Catan (Mayfair Games, Inc., 2015) in university-level EFL courses. Pedagogical applications beneficial for both types of gaming media in EFL contexts will also be outlined in this research.

ゲームベース学習は、目的言語を使用した交流を促進するという点で、英語教室でさまざまな実用的応用が可能となる。ゲ ームベース学習は、慎重にゲームを選択することで、幅広い指導戦略や指導目標、生徒の能力、興味などに、具体的に対応す ることが可能となる。ゲームベース学習が英語教室にもたらす多くの潜在的な利点を考えると、ゲームが英語教育の文脈で効 果的であるかどうかだけではなく、どのようなゲーム媒体が特定の文脈で最も効果的であるかに焦点をあわせる研究も必要 である。本研究では大学レベルの英語教育の場でクラウス・トイバーの『カタンの開拓者たち』(メイフェア・ゲームズ 2015) を対象に、ボードゲームとスマートフオンアプリの2種類のゲーム媒体の比較を行つたさらに本研究では、英語教育の文眽に おいて、両タイプのゲーム媒体に有益な教育的応用方法についても概説する。

he use of digital game-based learning (DGBL) in institutionalized academic settings has been evolving since the introduction of computers into the classroom (Caftori \& Paprzycki, 1997). The selection of digital games to potentially be used as pedagogical tools exploded as the golden age of video games dawned in the 1980s (Eddy, 2012). The field of DGBL continued to grow and expand alongside the newly-minted digital game industry as it entered the commercial market. As the global gaming market for digital games has grown considerably in scale, educators seeking to incorporate digital games into their classrooms now have a staggering amount of game choices to cater to any number of educational objectives, interests, levels, and contexts. Considering the everexpanding breadth of research identifying the potential advantages of utilizing DGBL in the classroom (Chiu, Kao, \& Reynolds, 2012), it begs the question: what, if any, are the advantages and disadvantages of utilizing digital games as pedagogical tools vis-àvis non-digital gaming media such as board games? It is this pertinent question that framed this study. In this paper, two editions, board game and smartphone application, of Klaus Teuber's The Settlers of Catan (Mayfair Games, Inc., 2015), hereinafter referred to as Catan, were used in two separate university-level EFL courses to identify the most beneficial applications for both media types.

\section{Digital Gaming Vs. Non-Digital Gaming}

On the surface, both non-digital GBL and DGBL share a lot of commonalities, especially when looking at how games, whether digital or otherwise, can be employed by educators as effective instructional tools in the classroom. Some D/GBL benefits identified by a number of researchers include creating a motivating and stimulating learning environment (Druckman, 1995; Garris et al., 2002), improving concentration and participation (Annetta, 2008; Barata et al., 2013), promoting critical awareness of discourse communities (Alberti, 2008; Squire, 2002), providing instant corrective feedback and opportunities for negotiation of meaning (Cornillie et al., 2012; Peterson, 2012), and teaching cooperation (Gentile et al., 2009). Considering the host of potential benefits provided by both types of gaming media, both options should be considered by educators interested in utilizing D/GBL curricula. What is perhaps the more valuable line of inquiry is not how these types of gaming media are similar, but how they are different. Addressing the differences between digital games and non-digital games requires us 
to consider the primary difference between the two gaming media: the computer. The essential difference between non-digital games, which require peers for the game to take place, and non-digital games, which almost always are designed with single-player functionality, can be most easily broken down into the difference between peer-mediated and computer-mediated instruction. This key difference in the medium of instruction creates a number of disadvantages related to the type of mediation for each media type, and as such, many of these potential disadvantages relating to DGBL stem from the computer itself.

Many of the disadvantages of game-based pedagogy that have been identified can be applied to both digital and non-digital gaming alike. Some of these shared disadvantages may include difficulties relating game content to institutionally predetermined curricula and/or pedagogical methodology (Baek, 2008), psychological issues such as addictive behavior resulting from commercially driven gameplay mechanics (Skoric et al., 2009), lack of supporting materials available for teachers and students to use in conjunction with gameplay (Baek, 2008), and fixed class schedules that are ill-suited to the large amount of time required to achieve game proficiency or to otherwise finish an entire game within one class (Squire, 2007). However, there are two disadvantages that are unique to computer-mediated instruction that may impede successful integration of DGBL curricula: digital illiteracy and budget/equipment limitations.

First, digital literacy is often associated with the socioeconomic status of a student (Cohron, 2015; Henderson \& Honan, 2008). Therefore, in any given classroom, there will be varying levels of inherent student abilities to interact with the necessary technology needed to successfully carry out DGBL curricula (Cohron, 2015; Steinkuehler, 2010). For students who do struggle with computer-mediated instruction due to lack of exposure to relevant technology, extra time may be required to ensure that such students acquire the ability to adequately interface with the incorporated technology to complete each lesson. Any extra time used to bring struggling students up to speed not only takes limited class time away from interacting with the digital game of instruction, but also decreases the amount of time that the instructor has to educationally mediate the interactions taking place between the students and the gaming software used.

Second, the expense of running DGBL curricula that require computer equipment, software, and a host of other potentially necessary components can all amount to an insurmountable financial hurdle in institutionalized education (Tüzün, 2007). While certain educational institutes have computer labs available for instructional purposes, this situation is far from universal and certainly does not guarantee that students have access to computers to continue with lesson content outside the classroom.
Furthermore, the cost of additional commercial gaming consoles and/or software must either be borne by the institute, the instructor, or the students. The large price tag that can accompany large-scale DGBL curricula in formal academic settings may deter the institute, instructor, and students from engaging in such pedagogical frameworks.

Considering the DGBL-specific disadvantages of varying levels of computer literacy among the student population and potentially high initial investment costs necessary for large-scale digital gaming, the case could be argued that for many academic institutions, game-based curricula that make use of non-digital games are potentially more efficacious. Indeed, if GBL curricula that employ non-digital games share similar pedagogical advantages to DGBL curricula while avoiding some of the computercentered pitfalls, then non-digital games would seem like the path of least resistance for institutionalized GBL. With that being said, technological advancement continues to reshape what is possible in the digital landscape. As will be argued in this study, the technological advancements of the past decade resulting in widespread smartphone use together with the subsequent evolution of commercial digital gaming markets to incorporate smartphone technology into game development directly address the two disadvantages of potential digital illiteracy and budget/equipment limitations specific to DGBL curricula.

\section{The Rise of Smartphone Gaming}

As the digital gaming industry continues to evolve, the industry of smartphone gaming continues to take a more leading role. Smartphone gaming is a $\$ 68.5$ billion industry which accounts for approximately $50 \%$ of the global gaming market (Newzoo, 2019). Additional surveys indicate that smartphones are the most widely used gaming device at $71 \%$, computers accounted for $64 \%$, tablets for $34 \%$, and console systems for just 26\% (TNS Global, 2016). This constant technological interaction has allowed smartphone applications to occupy "dead time" and increase the frequency of potential gaming sessions by reclaiming periods of time during which the use of conventional gaming platforms other than mobile gaming devices is impossible (e.g. riding on a train) Furthermore, the multipurpose consolidation of technological features engendered by smartphones necessarily set them apart from previous mobile gaming-only systems. It is this drastic shift in the gaming industry towards mobile gaming coupled with the high level of market penetration of the smartphone that has created a unique opportunity to address the aforementioned disadvantages that come with DGBL in formal academic settings. 
The effects of smartphone market penetration are not limited to shifting social perceptions of digital media. When it comes to digital literacy, exposure to relevant technology is indispensable. The multipurpose consolidation of technological features available on smartphones in conjunction with its mobility has driven many consumers to prioritize smartphone ownership over that of personal computers. According to market surveys, worldwide internet access from mobile devices crossed the $50 \%$ threshold in 2017 (BroadbandSearch, 2020). As people become more familiar with smartphone interfaces and applications, the amount of technical difficulties encountered by DGBL pedagogical frameworks that make use of smartphones in formal academic settings will arguably be reduced. This study, being conducted in a private Japanese university, also benefited from these high levels of market penetration as $94.2 \%$ of people in the $20-30$ age bracket in Japan possessed smartphones as of 2016 (Ministry of Internal Affairs and Communications, 2021)

The near universal smartphone penetration rate in higher education also goes a long way in easing the problem of access to necessary equipment to conduct DGBL curricula both inside and outside the classroom. By utilizing smartphone game titles in DGBL curricula, the costliest component of such pedagogical methods, namely the hardware is borne by the students and all but ensures the ability of students to participate in the lesson anytime and anywhere. However, the near universal smartphone penetration into the university age demographic does not solve other financial burdens potentially associated with DGBL curricula such as WiFi access, data consumption, or software cost. By the same token, access to smartphone devices does go a long way in reducing the financial investments needed to successfully run DGBL curricula in higher education.

The rise in smartphone gaming coupled with its increasing market penetration, as outlined above, is arguably shifting the digital landscape in such a way as to make pedagogical methods utilizing smartphone-based DGBL curricula a more efficacious approach than other forms of digital gaming. Smartphone-based DGBL learning therefore clearly represents a frontier with potential in the field of DGBL. These are the questions that must therefore be asked before going forward: (1) How is smartphonebased DGBL different from other types of non-digital gaming media, and (2) what are the most beneficial contexts for these types of gaming media in formal academic settings? The following section will detail how these questions were answered in this study.

\section{Methodology}

The two editions of Catan used in this study were the standard English language board game edition and the Catan Universe (Catan $\mathrm{GmbH}$, 2017) smartphone application. The
Catan Universe application was chosen because it is the official smartphone edition of the Catan gaming franchise, it is free to download and play, and the in-app tutorials and resources are available in English. The study goals were to use the same game in two different media platforms in order to (1) analyze the differences in implementation and educational outcome, if any, in each media type, and (2) identify specific contexts that may be potentially beneficial for future implementation of each media type.

\section{Data Analysis}

The data upon which the conclusions of this study are based were collected from two individual studies, one study focusing on the pedagogical implementation of the board game edition of Catan (Wrobetz, 2019) and one study focusing on the pedagogical implementation of the smartphone edition of Catan (publication forthcoming). The 2019 study researching the pedagogical implementation of the board game edition of Catan used post-game surveys to collect qualitative data and in-class observations/discussions to draw conclusions about the pedagogical effectiveness of board games in business English courses. The 2019 study researching the pedagogical implementation of the smartphone application edition of Catan collected participants' game data (win/loss data and total victory points from each gaming session) for quantitative analysis, used postgame surveys to collect qualitative data, and made in-class observations/discussions to draw conclusions about the pedagogical effectiveness of the smartphone gaming medium in business English courses. Both types of gaming media were argued to be effective pedagogical tools in business-oriented EFL courses. While it is outside the scope of this present study to provide an in-depth analysis of the results of each of these studies, the following section will outline the procedure and educational objectives for each study.

\section{Study Details and Educational Objectives}

The board game edition of Catan was implemented in a reading-oriented Business English course during the spring semester of 2019. A total of five students participated in three in-class gaming sessions with the board game edition of Catan in exchange for course credit and consented to the publication of data collected from these gaming sessions on the condition of anonymity. The $\mathrm{L} 1$ of all students in this study was Japanese and their overall English ability could be described using the proficiency guidelines provided by the American Council on the Teaching of Foreign Language (ACTFL) as being between intermediate low to intermediate mid for reading and writing and novice mid to novice high for speaking and listening (Breiner-Sanders et al., 2000). In-class 
observations and discussions were employed to ascertain how motivating the game was and how effectively students were using linguistic forms provided by the instructor for in-game negotiation purposes. Qualitative analysis was conducted with post-game surveys to help determine how effective the game was at eliciting explicit and implicit instruction on business-related concepts such as trade relations, negotiation strategies, supply and demand, resource management, and strategy development (Wrobetz, 2019).

The smartphone edition of Catan Universe was implemented in a Business English course during the fall semester of 2019. A total of four students participated in a minimum of four smartphone gaming sessions outside of class in exchange for course credit and consented to the publication of data collected from these gaming sessions on the condition of anonymity. The students were instructed that they would be able to participate in more gaming sessions if desired. Two of the four enrolled students completed more gaming sessions than was required. In contrast to the board game edition study, the students participating in the smartphone edition study did not compete against each other but rather with other registered players on the Catan Universe network. No specific instruction was given on how to play the game, and the students were told to use the in-app tutorials and online resources to learn how to play the game effectively. The $\mathrm{L} 1$ of three of the four students in this study was Japanese, and the L1 of the remaining student was Chinese. The overall English ability for all participating students could be described using the ACTFL proficiency guidelines as being between intermediate low to intermediate mid for reading and writing and novice mid to novice high for speaking and listening (Breiner-Sanders et al., 2000). In-class discussions were conducted to ascertain how motivating the game was. Participants' game data, specifically whether each game was won or lost and how many total victory points were achieved, were collected for the purpose of quantifying how successfully the students were acquiring game proficiency throughout the study period. These data are shown in Figure 1 and demonstrate that there is an observable trend reflecting improvements in game performance throughout the study period. Finally, qualitative analysis was conducted with both pre-game and post-game surveys in order to track how the participants' in-game strategies relating to concepts such as trade relations, negotiation strategies, supply and demand, and resource management changed over each gaming session.
Figure 1

Victory Points and Win Totals



\section{Results}

In order to ascertain how these two types of gaming media differ from each other in terms of their implementation in the courses outlined above, the next sections will focus on identifying key study observations that are not only unique to each gaming media type, but also point to the potential pedagogical advantages and disadvantages of each method. The observations that will be outlined in the next sections were collated from the analysis of the two studies listed in the methodology section which investigated the pedagogical potential of both media types of Catan.

\section{Board Game Edition Advantages and Disadvantages}

The potential pedagogical advantages observed with the board game edition of Catan primarily stem from the shared game experience. First, during the three in-class gaming 
sessions, the instructor was able to actively observe, participate in, and provide specific instruction on the aforementioned educational objectives during gameplay. Furthermore, due to the small class size in the study, every student was able to receive equal amounts of instructor feedback during gameplay. Second, the active role of the instructor during gameplay allowed for a sufficient amount of monitoring of students' $\mathrm{L} 1$ use, which resulted in high levels of sustained L2 use. Finally, although there was sufficient materia provided by the game for reading exercises, passive interaction with the game was not enough and students were also forced to communicate with other players to move the game forward, resulting in opportunities for students to hone their L2 speaking/listening skills as well.

The potential disadvantages of the board game edition of Catan primarily stem from the limited amount of exposure the students had to the GBL pedagogical framework. First, playing board games in class required a large investment of class time. Additional instruction on the content of gameplay occurred on lecture days after gameplay had concluded. Second, assuming that the students did not go out and buy a copy of the board game and organize their own gaming sessions, interaction with the gameplay mechanics and any concomitant pedagogical benefits was limited to the classroom environment. Finally, the gameplay mechanics of Catan can only accommodate four players at once, meaning that, for this study's class size of five, two students were paired together to act as a single-player entity during the three gaming sessions. This method of creating teams for joint gameplay did not pose much of an issue in this study, but for classes with larger enrollment figures, the limited number of students that are able to participate in any one game could create a disruption in how much game interaction each participating student receives.

\section{Smartphone Edition Advantages and Disadvantages}

The potential pedagogical advantages observed with the smartphone edition of Catan primarily stem from the ability to outsource all gameplay as homework, allowing more time during the semester for students to interact with the game mechanics. When compared to the three gaming sessions completed in the board game edition study, each of the four participating students in the smartphone edition study completed a minimum of four gaming sessions with two of the four students completing six and seven gaming sessions respectively. Second, although students were not given any specific instructions on how to play the game, students were able to exercise agency over their learning process, use the in-app English language tutorials and other outside resources such as YouTube tutorials, online strategy guides, and game-related discussions with each other to continually improve upon their performances throughout the semester. These improvements are evidenced in the gameplay data shown in Figure 1. Finally, each student was able to download the Catan Universe application for free with no technical difficulties as observed in this study, meaning that the pedagogical framework of this study could potentially be scaled up to a class size of any number of students, assuming that everyone enrolled has a smartphone with access to the Catan Universe application.

The potential disadvantages observed with the smartphone edition of Catan primarily stem from the isolated gaming experience. First, the streamlined interface of the gameplay mechanics in the Catan Universe application means that the players do not actually have to produce any language to interact with the other players on the network. Although the application does have a chat function, in this study it was only used to solve network connectivity issues. All other in-game interactions that would otherwise be conducted orally in the board game edition can be conducted with the push of a function-specific button in the smartphone edition. Second, as the students played the game as homework outside class, it was difficult to provide feedback on their in-game language use and to monitor what language the students used for their game resources. Finally, although the Catan Universe application does have a feature which allows the user to invite specific users to play with, all invited players must purchase the full version of the application, meaning that in order to bypass the disadvantages rooted in the isolated gaming experience offered by the free version of the application, the cost of the full version application would have to be borne by the institution, instructor, or students. This private-game feature was not used in this study because of the costs associated therewith.

\section{Discussion of Future Implementation}

The advantages and disadvantages in both gaming media as outlined above may inform how educators can integrate either smartphone gaming or board game media in the most effective way possible to suit their unique educational situation. Therefore, this next section will provide educators with an outline of potentially beneficial contexts for each media type.

\section{Beneficial Contexts for Board Games}

Board games, as observed in this study, provided a shared gaming experience that required sustained interaction with all players involved to move the game forward. 
In this sense, board games may be better suited for courses in which the educational objectives are to focus on improving L2 communication skills. Furthermore, since many board games only accommodate a handful of players, the instructor can efficiently provide corrective feedback and situationally specific instruction based on gameplay mechanics to each individual student. By the same token, however, board games may also be more conducive to smaller class sizes. Although it is possible to integrate board games into larger class sizes with multiple copies or student teams, this may not only inhibit the possibility of the instructor to monitor students' $\mathrm{L} 1$ use and provide corrective feedback but also reduce the amount of gameplay exposure for each student. Finally, due to the time-consuming nature of many board games, curricula that use this gaming media as their primary focus for the entire semester may achieve better pedagogical outcomes than those that use board games for short side projects.

\section{Beneficial Contexts for Smartphones}

Smartphones, as observed in this study, provide an isolated gaming experience that was outsourced as homework, allowing students to take more time in the semester to interact with the game mechanics and exercise agency over their education. In this sense, smartphones may be better suited for courses in which the educational objectives are more focused on improving passive language skills rather than productive skills and acquiring game proficiency. The streamlined interface of many smartphone gaming applications reduces the amount of oral communication between network players. Furthermore, there are fewer chances for the instructor to provide corrective feedback on any language production that could be occurring during gameplay. On the other hand, the isolated, single-player nature of many smartphone gaming titles means that the pedagogical framework may be scaled up to accommodate any number of enrolled students. Finally, pedagogical frameworks that incorporate board games may limit students' agency over their own learning when the students do not own their own copy of the game for use outside of class. Conversely, pedagogical frameworks that incorporate smartphone gaming applications may act to encourage students' agency by ensuring the ability to interact with the gameplay mechanics outside the classroom environment.

\section{Conclusion}

As has been evidenced and argued in this study, smartphone gaming represents the next frontier of DGBL research. The proliferation of smartphone gaming into the global gaming market and into the pockets of consumers (and students) should prompt research into how the medium of smartphone gaming may differ from other gaming media in the wider realm of GBL. As outlined in this study, smartphone gaming may address specific disadvantages stemming from computer-mediated instruction within DGBL curricula through the increased familiarity with relevant technology and reduction in the costs associated with operating large-scale DGBL projects. This conclusion, however, does not discount the potential of non-digital games to achieve different pedagogical outcomes in different educational contexts. By analyzing how both the digital and non-digital editions of The Settlers of Catan elicited varied applications in university-level EFL courses, the importance of selecting the most appropriate gaming media for game titles with multimedia platforms has been emphasized. Future research on the topic of media selection in D/GBL pedagogical frameworks should address how both digital and nondigital gaming media may be used in conjunction with one another to capitalize on the potential pedagogical benefits afforded by each media type. While instructors utilizing D/GBL curricula may not get to choose the educational context in which they are employed, expanding choices in gaming media formats have added one more tool with which to create the most efficacious learning environment possible.

\section{Bio Data}

Kevin R. Wrobetz is a lecturer in the Department of Business Administration at Kobe Gakuin University and a Ph.D. candidate at Kyoto University. His primary area of research is game-based vocabulary acquisition.

\section{References}

Alberti, J. (2008). The game of reading and writing: How video games reframe our understanding of literacy. Computers and Composition, 25(3), 258-269. http://citeseerx.ist.psu.edu/viewdoc/downlo ad?doi=10.1.1.1043.6776\&rep=rep1\&type $=$ pdf

Annetta, L. A. (2008). Video games in education: Why they should be used and how they are being used. Theory into practice, 47(3), 229-239. https://citeseerx.ist.psu.edu/viewdoc/download?doi=1 0.1.1.455.2684\&rep=rep1\&type $=$ pdf

Baek, Y. K. (2008). What hinders teachers in using computer and video games in the classroom? Exploring factors inhibiting the uptake of computer and video games. CyberPsychology \& Behavior, 11(6), 665-671. https://www.academia.edu/download/30541768/Baek.2008.pdf 
Barata, G., Gama, S., Jorge, J., \& Gonçalves, D. (2013, October). Improving participation and learning with gamification. In Proceedings of the First International Conference on gameful design, research, and applications (pp. 10-17). https://www.academia.edu/download/39691110/ Improving_Participation_and_Learning_wit20151104-4872-doief2.pdf

Breiner-Sanders, K. E., Lowe, P., Miles, J., \& Swender, E. (2000). ACTFL proficiency guidelinesSpeaking (Revised 1999). Foreign Language Annals, 33(1), 13.

BroadbandSearch. (2020). Mobile Vs. Desktop Internet Usage (Latest 2020 Data). Retrieved from https://www.broadbandsearch.net/blog/mobile-desktop-internet-usage-statistics

Caftori, N., \& Paprzycki, M. (1997). The design, evaluation and usage of educational software. In Society for Information Technology \& Teacher Education International Conference (pp. 23-27). Association for the Advancement of Computing in Education (AACE).

Chiu, Y. H., Kao, C. W., \& Reynolds, B. L. (2012). The relative effectiveness of digital game-based learning types in English as a foreign language setting: A meta-analysis. British journal of educational technology, 43(4), E104-E107.

Cohron, M. (2015). The continuing digital divide in the United States. The Serials Librarian, 69(1), 77-86.

Cornillie, F., Clarebout, G., \& Desmet, P. (2012). The role of feedback in foreign language learning through digital role-playing games. Procedia-Social and Behavioral Sciences, 34, 49-53. https:// www.sciencedirect.com/science/article/pii/S1877042812003163/pdf?md5=454cc083d802b00e7 ec4368e6bab590d\&pid=1-s2.0-S1877042812003163-main.pdf\&_valck=1

Druckman, D. (1995). The educational effectiveness of interactive games. In Simulation and gaming across disciplines and cultures: ISAGA at a watershed (pp. 178-187). Sage Publications.

Eddy, B. R. (2012). Classic Video Games: The Golden Age 1971-1984. Bloomsbury Publishing.

Garris, R., Ahlers, R., \& Driskell, J. E. (2002). Games, motivation, and learning: A research and practice model. Simulation \& gaming, 33(4), 441-467. https://journals.sagepub.com/doi/ pdf/10.1177/1046878102238607

Peterson, M. (2012). Learner interaction in a massively multiplayer online role playing game (MMORPG): A sociocultural discourse analysis. ReCALL, 24(03), 361-380. https://repository. kulib.kyoto-u.ac.jp/dspace/bitstream/2433/168065/3/S0958344012000195.pdf

Gentile, D. A., Anderson, C. A., Yukawa, S., Ihori, N., Saleem, M., Ming, L. K., Shibuya, A., Liau, A.K., Khoo, A., Bushman, B.J., Huesmann, L.R., \& Sakamoto, A. (2009). The effects of prosocia video games on prosocial behaviors: International evidence from correlational, longitudinal, and experimental studies. Personality and Social Psychology Bulletin, 35(6), 752-763. https://journals. sagepub.com/doi/pdf/10.1177/0146167209333045

Henderson, R., \& Honan, E. (2008). Digital literacies in two low socioeconomic classrooms:

Snapshots of practice. English Teaching: Practice and Critique, 7(2), 85-98. https://eprints.usq.edu. au/4375/2/Henderson_Honan_2008_PV.pdf
Ministry of Internal Affairs and Communications. (2021). スマートフォン個人保有率の推移 [Trends in individual smartphone ownership rates]. Retrieved from https://www.soumu.go.jp/ johotsusintokei/whitepaper/ja/h29/html/nc111110.htm

Newzoo. (2019). Global Games Market Report. Retrieved from https://newzoo.com/insights/ articles/the-global-games-market-will-generate-152-1-billion-in-2019-as-the-u-s-overtakeschina-as-the-biggest-market/

Skoric, M. M., Teo, L. L. C., \& Neo, R. L. (2009). Children and video games: Addiction, engagement, and scholastic achievement. Cyberpsychology \& behavior, 12(5), 567-572.

Squire, K. (2002). Cultural framing of computer/video games. Game studies, 2(1), 1-13. https:// www.academia.edu/download/51033216/41-Game_20Studies_200102_20Cultural_20framing _20of_20computer_video.pdf

Squire, K. (2007). Open-ended video games: A model for developing learning for the interactive age. MacArthur Foundation Digital Media and Learning Initiative. https://cdn-educators.brainpop. com/wp-content/uploads/2013/10/squire-open-ended-games-macarthur-salen.pdf

Steinkuehler, C. (2010). Video games and digital literacies. Journal of Adolescent \& Adult Literacy, 54(1), 61-63. https://go.gale.com/ps/i.do?id=GALE\%7CA237733152\&sid=googleScholar\&v=2.1\&i $\mathrm{t}=\mathrm{r} \&$ linkaccess $=$ fulltext\&issn $=10813004 \& \mathrm{p}=\mathrm{AONE} \& \mathrm{sw}=\mathrm{w}$

Teuber, K. (2015). The Settlers of Catan. Mayfair Games, Inc

Teuber, K. (2017). Catan Universe. Catan GmbH.

TNS Global. (2016). 5 Global Mobile Gaming Trends. Retrieved from https://www. socialmediatoday.com/social-business/facebook-conducts-research-opportunities-mobilegaming-infographic

Tüzün, H. (2007). Blending video games with learning: Issues and challenges with classroom implementations in the Turkish context. British Journal of Educational Technology, 38(3), 465 477. http://www.openaccess.hacettepe.edu.tr:8080/xmlui/bitstream/handle/11655/20204/ Blending\%20Video\%20Games\%20With.pdf?sequence=2

Wrobetz, K. R. (2019). Board games in business English: Using the Settlers of Catan to teach business concepts in a foreign language. 神戸学院大学経営学論集 [Academic Journal of the Department of Business Administration, Kobe Gakuin University], 16(1), 1-17. https://www. researchgate.net/publication/336577951_Board_Games_in_Business_English_Using_Settlers of_Catan_to_Teach_Business_Concepts_in_a_Foreign_Language 